\title{
THEORY AND PRACTICE IN THE USE OF MERGER REMEDIES: CONSIDERING SOUTH AFRICAN EXPERIENCE
}

\author{
Genna Robb* \\ U) Centre for Competition Economics \\ gennar@compcom.co.za \\ Avias Ngwenya \\ UJ Centre for Competition Economics \\ The Competition Commission of South Africa \\ aviasn@compcom.co.za
}

April 2011

\begin{abstract}
There has been considerable debate internationally around the relative advantages and disadvantages of structural and behavioural remedies. In mergers which raise competition concerns, prohibition or divestiture may prevent merger efficiencies from being realised, and therefore behavioural remedies may seem attractive. However, these can prove difficult or impossible to enforce in practice. The merger approval rates of the South African competition authorities are in line with the practice of international agencies, but the number of behavioural remedies imposed is relatively high. This paper briefly considers the international literature on merger remedies before analysing South African merger decisions and making a comparison with other jurisdictions. It then presents a review of a decision made by the Tribunal in the merger between Astral Foods and National Chick in 2001, which was approved with both structural and behavioural conditions. Finally, the paper draws conclusions for the design of remedies in future.
\end{abstract}

Keywords

Merger, remedy, behavioural, structural, South Africa

\footnotetext{
* Ms Genna Robb is an associate of UJ Centre for Competition Economics and an Economist at the Competition Commission, South Africa.

\# Mr Avias Ngwenya is an associate of UJ Centre for Competition Economics and an Economist at the Competition Commission, South Africa.
}

The views expressed in this paper are those of the authors and do not necessarily represent the views of UJ Centre for Competition Economics and the Competition Commission South Africa 


\section{INTRODUCTION}

Merger remedies are conditions that the competition authority (CA) may impose on merging parties in order for a merger to be permitted in cases where it is likely that competition in the relevant market will be negatively impacted by the transaction. The alternative to imposing a remedy (or package of remedies) is the outright prohibition of the merger, an outcome which may not be optimal if there are significant efficiency gains to be realised from the merger. The aim of merger remedies is therefore "to enable a modified outcome to merger transactions which restores or maintains competition while permitting the realisation of relevant merger benefits" (International Competition Network (ICN), 2005).

This is easier said than achieved in practice, and there has been significant debate over the best kind of remedies to use. In particular, the advantages and disadvantages of the two main types of remedy, structural and behavioural, have been much discussed. Structural remedies involve a one-off intervention to restore the pre-merger level of competition in the industry, usually by requiring the merging parties to divest part of the business to an independent party. This is attractive to the $C A$, as it does not require on-going attention or monitoring and can achieve the desired outcome in a straightforward and lasting fashion. There are also difficulties associated with structural remedies, however, as the degree of information and incentives held by the CA and the merging parties are not well-aligned, leading to problems with implementation. Furthermore, there is not always an obvious and neat divestiture package of which to dispose and the sale may reduce or eliminate the efficiencies associated with the merger. Despite these shortcomings, however, a number of CAs, including those in the EC, US and UK, have all expressed preferences for the use of structural remedies wherever possible.

Behavioural remedies, on the other hand, represent an on-going commitment by the merging parties to constrain their behaviour in such a way that the level of competition will not be diminished by the merger. These undertakings take the form of agreements to provide, inter alia, access to competitors to essential facilities or inputs and licence technologies, or to put limits on the shareholding or appointment of directors of the merging parties. Behavioural remedies can be less disruptive and costly to the merged entity than divestiture, and can provide an alternative when structural remedies are either not possible, or would result in merger efficiencies being lost. However, they may require monitoring and enforcement by the CA in order to be effective, which can make them costly, or in the case that monitoring is not carried out, ineffective. A number of jurisdictions, including France, Spain, Italy, Switzerland and the Eastern European bloc of countries, favour the use of behavioural remedies.

In this context, the paper uses data compiled from Competition Commission and Tribunal records in order to consider South African policy and experience in using merger remedies. It aims to determine where South Africa is placed in this debate, and to test how well-aligned this position is with international approaches. Where differences exist in preferences across countries, we advance some hypotheses which could potentially explain the divergence. The paper also seeks to identify issues associated with using remedies in practice and to draw conclusions for the appropriate use of different types of remedy in South Africa.

The paper proceeds as follows. Section 2 discusses recent literature on the topic of remedies in order to draw out the theoretical advantages and disadvantages of each type of remedy. Section 3 then goes on to analyse the approach taken by CAs in different jurisdictions and to compare this with the South African experience. Finally, in Section 4 a case study of a review of a particular South African merger where both structural and behavioural conditions were imposed 
is used to highlight some of the difficulties with each. Section 5 concludes by summarising the main findings of the paper and their implications for merger policy in South Africa, and goes on to suggest possible avenues for future research.

\section{LITERATURE REVIEW}

Before discussing the relative merits of behavioural and structural remedies, it is useful to define precisely what is meant by each. The ICN (2005) describes the different types of remedy that can be applied by the CA according to the diagram below.

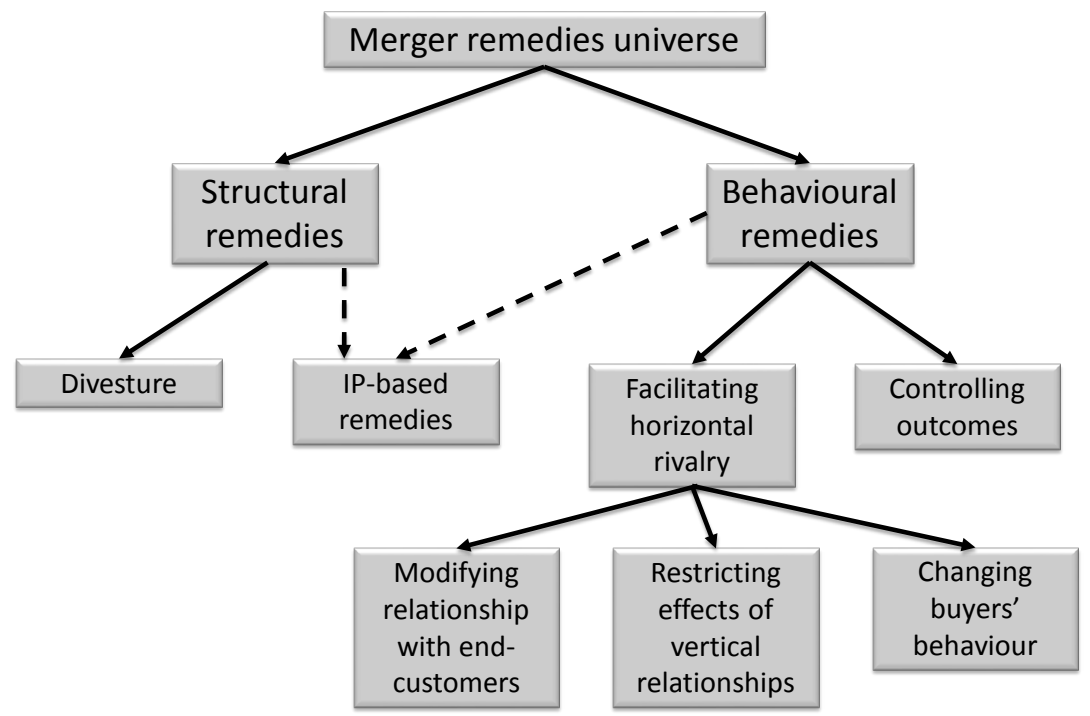

\section{FIGURE 1: Types of merger remedy}

\section{Source: ICN, 2005}

Structural remedies represent a one-off intervention to restore the competitive structure of the market by modifying the allocation of property rights (Motta, 2005). Most often, this consists of the divestiture of a part or parts of the merged firm's business to a new or established market participant in order to restore an effective competitor to the market. A structural remedy can also involve the divestiture or licensing of intellectual property (IP). IP-based remedies can be structural or behavioural, but are classified as structural when they represent a one-off interaction between the merged firm and other market participants - in other words when the agreement is "exclusive, irrevocable, and non-terminable with no on-going royalties" (ICN, 2005:13).

Behavioural remedies, on the other hand, are characterised as on-going interventions aimed at modifying or constraining the behaviour of the merged firms. Or as Motta (2005) puts it, they set constraints on the merged firm's property rights. For example, firms are obliged to undertake not to abuse certain assets or to enter into certain contractual arrangements. There are three main types of behavioural remedy (ICN, 2005). The first, IP-based remedies, fall into the behavioural 
category when they require an on-going relationship between the merged party and the licensee. The second, remedies to facilitate horizontal rivalry, can be further broken down into three categories. Remedies that modify relationships with end customers are intended to prevent the merged firm from using its horizontal market position to foreclose competitors and may include measures to prevent tying and bundling, predatory pricing or the use of exclusive contracts. Those that restrict the effects of vertical relationships aim to prevent a firm from using its vertical position to foreclose competition in horizontal markets by, for example, mandating access to necessary inputs and the price which can be charged for those inputs. Finally, remedies aimed at changing buyers' behaviour seek to encourage competition by giving customers greater countervailing power, for example through giving customers better access to information or increasing the ease with which they can switch suppliers.

Controlling outcomes is the final type of behavioural remedy, and refers to interventions that seek to directly control outcomes such as price and range of products through price caps, service level agreements, supply commitments etc. (ICN, 2005).

\subsection{Advantages and disadvantages of structural remedies}

Structural remedies are attractive to the $\mathrm{CA}$, as they do not require on-going monitoring and intervention: if they are well-designed and implemented they should solve competition concerns in a one-off transaction. Nevertheless there is risk associated with structural remedies, as they are generally irreversible and face various challenges in effective implementation, most of which stem from the lack of alignment of the incentives of the various parties involved. The CA, in trying to restore the pre-merger level of competition to the market, is naturally concerned with ensuring that the firm that acquires the divested assets has the capacity to be a strong competitor. On the other hand, the merging parties would generally prefer the opposite outcome. A further complication ensues from informational asymmetries, since in many cases the merging parties understand the value of the assets being divested better than the CA or an outside firm can. A study of divestitures carried out by the US Federal Trade Commission (FTC, 1999) showed that often buyers did not have enough information to prevent mistakes in the course of the acquisition of divested assets. These difficulties result in a number of risks to the divestiture process, which the ICN (2005) has classified under the headings of composition risk, purchaser risk and asset risk.

Composition risk refers to the scope of the divestiture package. The CA may require the divestiture of a whole business unit, or a collection of assets, from one or both of the merging parties. The composition of the divestiture package is important, as it must be sufficient to allow the purchasing firm to be an effective competitor - in other words, the divested assets must be able to function as a viable business. The problem of information asymmetries is significant here, since it may not be so clear to outsiders, particularly to a new entrant to the market, whether the divestiture package meets this criterion or not. The FTC study mentioned above found that the likelihood of successful entry was much higher when an entire on-going business, and not just selected assets, was divested (FTC, 1999).

The problem of purchaser risk arises due to the difficulty of finding a suitable buyer for the divested assets, either because one is not available, or as a result of the misaligned incentives of the merging parties. The parties would generally like to sell to a weak buyer, in order to reduce the competitive threat of the divested firm post-merger. The FTC study found evidence that the merging parties did indeed tend to identify weak buyers (FTC, 1999). 
Finally, asset risk exists due to the danger that the buyer's ability to compete post-divestiture will be compromised due to the deterioration of the assets prior to their sale. For example, the firm may lose customers or key staff members. The misaligned incentives of the merging firm can also be important here, as it is in the firm's direct interest to cause this to happen. Empirical evidence (UK Competition Commission (UK CC), 2010; European Commission ( $\varepsilon C$ ), 2005) has shown that asset value can deteriorate in the interim in some cases and it is important to put provisions in place to prevent this outcome.

A further difficulty with structural remedies is noted by Motta, Polo and Vasconcelos (2002). These authors argue that structural remedies can in some cases increase the likelihood of collusion in an industry. This could be the case particularly if the divestiture creates symmetry between the businesses of the buyer and the seller or if the two have multi-market contacts. Collusion is also more likely if there has to be an on-going relationship between the buyer and seller post-merger - for example if the buyer needs access to certain inputs or technical assistance. The authors suggest that it would be appropriate to apply a similar two-part test to that used by the European Commission for assessing the possible unilateral and coordinated effects of mergers, in order to evaluate if the divestiture is likely to lead to any unilateral or pro-collusive effects.

The foregoing discussion illustrates why structural remedies may not be as straightforward as they first seem, a conclusion that is borne out by experience. The European Commission's expost assessment of merger remedies $(\varepsilon C, 2005)$ highlights the risks associated with structural remedies. The study evaluated 40 decisions and 96 remedies imposed by the $\varepsilon C$ between 1996 and 2000, aiming to assess the design and implementation of the remedies. Transfer remedies (or divestitures) were found to be effective in only $56 \%$ of cases and partially effective in a further $25 \%$. The market share of the divested business decreased in $44 \%$ of the cases (in some cases by more than $50 \%$ ) and remained stable in $34 \%$. The retained business often outperformed the divested one ( $57 \%$ of cases). This could indicate that the merged firm was competing aggressively; however, it may also be that some of the difficulties described above were encountered.

Specifically, the $\varepsilon C$ study found that the scope of the divestiture was the most serious threat to its effectiveness, and problems were noted with the scope in $79 \%$ of cases. Purchaser risk was also an issue in $48 \%$ of cases and there were 11 cases where the choice of the 'wrong' purchaser led to serious unresolved problems. The study also found that in $37 \%$ of cases the effectiveness of the remedy risked being, or was, reduced as a result of difficulties in preserving the value of the assets in the interim period ( $\varepsilon C, 2005)$.

Papandropoulos and Tajana (2006) note that the $\varepsilon C$ remedies review confirms that merging parties often behave strategically when obliged to divest part of the business. The authors suggest that there is also the possibility that buyers of divested assets/concerns act strategically, since they also have an interest in limiting competition post-merger.

However, there are a number of ways of counteracting the difficulties associated with structural remedies. As noted in the previous section, the divestiture of a standalone business should be preferred to that of a mixture of assets, as it lowers composition risk associated with divestiture and increases the likelihood of there being an effective competitor post-merger. It may also reduce purchaser risk, since in the sale of a mixture of assets, the capability and assets of buyer become much more important for the success of the transaction (ICN, 2005). Some CAs make use of an up-front buyer provision that obliges merging parties to secure a buyer before the merger is allowed to proceed. This was found to be useful in both the $\varepsilon C$ and UK remedies reviews, as it 
reduced the risk of not finding a suitable purchaser ( $દ C, 2005$; UK CC, 2010). A divestiture trustee can be used to monitor the divestiture process, to enforce "hold-separate" conditions (when merging firms are required to keep the divested business separate from the retained business in the interim period) and to make sure that the quality of the assets does not deteriorate before sale. As noted by Papandropoulos and Tajana (2006), the longer the divestiture period, the greater the need for effective interim measures and hold-separate provisions in order to maintain the value of the assets. In some jurisdictions a "crown jewels" provision is used, where the CA defines a broader, more readily-divested group of assets that must be divested if the original package is not divested within the specified time limit (ICN, 2005). Finally, a review of remedies conducted by the UK Competition Commission (UK CC, 2010) found that it is important to investigate in detail the business plan of the buyer for the acquired assets prior to the sale, in order to reduce purchaser risk.

\subsection{Advantages and disadvantages of behavioural remedies}

Behavioural remedies are often considered to be more complex than structural remedies and to require greater effort on the part of the CA to implement effectively. The main disadvantage associated with behavioural remedies is that they often require on-going monitoring by the CA, and may be evaded if this monitoring does not take place, or if the CA does not know the industry well (Motta et al., 2003). They may be difficult for the CA to enforce, since it does not have the in-depth knowledge of the industry or monitoring capacity that a regulator would have. On the other hand, if there is already an industry regulator in place, or where monitoring can be carried out by market participants, behavioural remedies may have relatively low monitoring costs (Papandropoulos \& Tajana, 2006).

Remedies aimed at preventing vertically integrated firms from following strategies to foreclose horizontal competitors are not straightforward, since such strategies may take a number of forms and not be based on price alone. Other possible strategies include reduced quality, delayed supply etc. This makes enforcement difficult. The $\varepsilon C$ remedies study found that access remedies were unlikely to be effective; however, this may be due to the small sample size in the study ( $\varepsilon C, 2005)$.

The licensing of technologies can also be problematic, as it often calls for a temporary collaboration between the merged entity and the licensee, and the merged entity may not have the incentive to cooperate effectively (Motta et al., 2003).

Remedies aimed at regulating and limiting prices can be counter-productive, since by reducing the possible profits that firms can make, they will also reduce the incentive for entry (ICN, 2005). Thus they may be appropriate only where entry barriers are high and entry unlikely. Furthermore, the decision of what price to set can be extremely complex and may need to be adjusted over time, requiring prolonged $C A$ intervention in the market.

The ICN (2005) study concludes that behavioural remedies may be appropriate in the following circumstances: when a structural remedy is not feasible or would be very risky and where prohibition is not feasible; when competitive detriments caused by the merger are expected to be of limited duration; and, when the merger benefits are believed to be significant. Papandropoulos and Tajana (2006) argue that behavioural remedies are more appropriate for vertical mergers, particularly to prevent vertical foreclosure, and also in situations where a sector regulator already exists.

A final point to note in relation to the choice of remedy is that approving a merger with 
conditions may not always be the optimal outcome. Seldeslachts, Clougherty and Barros (2007) conducted a study to consider the deterrence effects of merger control, i.e. the impact of the CA's merger decisions on firms' likelihood of engaging in anti-competitive mergers in future. According to the authors, this factor is generally thought to be important but has rarely been empirically tested. The study finds evidence that merger prohibitions have a deterrence effect with respect to future merger frequencies, whereas remedies do not. The study looks at merger frequency effects only, and not composition effects (e.g. whether firms structure mergers more efficiently), so one cannot definitively conclude that prohibitions result in fewer anticompetitive mergers and remedies do not. However, the authors note that in a world of resource constraints, the frequency results alone may be important, as increased merger frequency increases the burden of cases for the CA to review.

\section{INTERNATIONAL COMPARISON}

As highlighted in the literature review presented above, there is still a great deal of debate over the advantages and disadvantages of different types of remedy. This is reflected in the merger policy followed in different jurisdictions - some with an explicit preference for one or other type, and others being more balanced.

The $\varepsilon C$ has a stated preference for structural remedies:

commitments which are structural in nature, such as the commitment to sell a business unit, are, as a rule, preferable from the point of view of the Merger Regulation's objective, inasmuch as such commitments prevent, durably, the competition concerns which would be raised by the merger as notified, and do not, moreover, require medium or long-term monitoring measures. (EC notice on acceptable remedies, 2008:13)

It considers behavioural remedies appropriate "only exceptionally in very specific circumstances" ( $(C, 2008: 17$ ). This tallies with data from the $\varepsilon U$ merger remedies study ( $દ C$, 2005). Between 1996 and 2000, the $\varepsilon C$ approved 91 mergers with conditions, which resulted in 227 remedies being imposed. Of these, $10 \%$ can be classified as behavioural remedies, and $84 \%$ structural ( $6 \%$ fall into a category described as 'other'). Interestingly, and in contrast to the approach of the South African authorities, the $\varepsilon C$ does not regard undertakings by the merging parties not to engage in anti-competitive behaviour as sufficient to allay their concerns in the case of horizontal issues, regardless of the ease and cost of monitoring and enforcement, stating that:

In particular, commitments in the form of undertakings not to raise prices, to reduce product ranges or to remove brands, etc., will generally not eliminate competition concerns resulting from horizontal overlaps. (EC, 2008:17)

The merger remedy guidelines issued by the US Department of Justice (US DOJ, 2004) state that:

Structural remedies are preferred to conduct remedies in merger cases because they are relatively clean and certain, and generally avoid costly government entanglement in the market... A conduct remedy, on the other hand, typically is more difficult to craft, more cumbersome and costly to administer, and easier than a structural remedy to circumvent. (US DOJ, 2004)

The US DOJ finds behavioural remedies to be appropriate only in circumstances where conduct 
modification is necessary to support an effective structural remedy (for example, restrictions on the merged entity's ability to re-hire personnel from the divested business for a certain period of time in order to maintain its viability as a competitor), or where there are significant economies to be gained from a merger but a divestiture is either not feasible or would result in the loss of these efficiencies (US DOJ, 2004). The DOJ remedy guidelines state that behavioural remedies are rarely preferred and generally only in industries that are already closely regulated. This is reflected in the data. Between 1 October 1993 and 30 September 2003, the Antitrust Division of the DOJ filed 113 merger cases. Fewer than ten were approved with behavioural conditions without any structural remedy, and most of those cases involved the regulated telecommunications industry and the defence industry (US D0J, 2004).

Hoehn (2009) considers the remedies practice in seven European countries, showing that countries can be clearly grouped into those that prefer structural remedies (UK, Netherlands and Germany) and those that use more behavioural remedies (France, Spain, Italy and Switzerland). The paper suggests that this divide may be affected by the level of development of competition policy in a country, with the "more established" authorities tending to favour structural remedies because they have become "tougher" with experience. This hypothesis is further supported by evidence from the Merger Remedies Matrix (Clifford Chance and PricewaterhouseCoopers, 2008), which reveals findings from a Europe-wide merger remedy data collection project. This data shows a strong preference for the use of behavioural commitments across the Eastern European bloc of countries, supporting the idea that less mature CAs apply a greater proportion of behavioural remedies.

In order to compare South Africa's merger policy with other jurisdictions we compiled a database of the conditional approvals granted by the Commission and the Tribunal between 2000 and 2009. The results are shown in TABLE 1.

South African merger policy over the period shows a marked preference for behavioural remedies over structural remedies, with a higher proportion of behavioural remedies used than all the other comparator countries. South Africa clearly fits into the grouping with Spain, Switzerland, Italy and France. According to the hypothesis advanced by Hoehn (2009), this would reflect the fact that the South African competition authorities are less experienced than their northern European counterparts.

However, Hoehn (2009) also notes that it may simply be that different industries and different competition issues in each country impact on the types of remedies that are appropriate. This is borne out to some extent by the evidence. As reported in the paper, there is a clear preference across all seven countries for behavioural remedies in cases involving network and infrastructure industries, where access remedies are prominent. On the other hand, in wholesale and retail industries structural remedies are more popular, particularly in the case of horizontal competition issues.

An analysis of types of remedy used across industries in South Africa did not show any striking trends, however, partly since the majority of remedies (56\%) were in the manufacturing sector, which left a relatively small sample size in each of the other sectors.

Much more revealing was drawing a distinction between vertical and horizontal mergers, and analysing types of remedy employed in each. As illustrated in TABLE 2, the South African CAs exhibit a much stronger preference for behavioural remedies in vertical mergers than in horizontal mergers. 
TABLE 1: Merger remedies in selected European countries and South Africa, 2000-2008

\begin{tabular}{lccc}
\hline & Structural & Behavioural & Mixed \\
\hline UK & $71.4 \%$ & $23.2 \%$ & $5.4 \%$ \\
Netherlands & $68.4 \%$ & $26.3 \%$ & $5.3 \%$ \\
Germany & $55.0 \%$ & $22.5 \%$ & $22.5 \%$ \\
& & & \\
South Africa & $32.3 \%$ & $53.8 \%$ & $13.8 \%$ \\
Spain & $32.1 \%$ & $50.0 \%$ & $17.9 \%$ \\
Switzerland & $27.3 \%$ & $54.5 \%$ & $18.2 \%$ \\
Italy & $26.1 \%$ & $30.4 \%$ & $43.5 \%$ \\
France & $17.5 \%$ & $38.6 \%$ & $43.9 \%$ \\
\hline Source: & Hoehn (2009), Competition Tribunal of South Africa, Competition Commission of \\
& & &
\end{tabular}

This is in line with the stated policies of the $E C$ and US DOJ, as discussed above. However, South Africa still uses more behavioural remedies than structural remedies in horizontal mergers, which represents a marked divergence from policies followed in those jurisdictions. The EC believes that it is unlikely a behavioural remedy will be effective in a merger that presents horizontal competitive concerns.

TABLE 2: Merger remedies in horizontal and vertical mergers in South Africa, 2000-2009

\begin{tabular}{lcccc} 
& Structural & Behavioural & Both & Total mergers \\
\hline Horizontal & $39 \%$ & $42 \%$ & $18 \%$ & 38 \\
Vertical & $12 \%$ & $76 \%$ & $12 \%$ & 17 \\
Both & $20 \%$ & $80 \%$ & $0 \%$ & 5 \\
\hline
\end{tabular}

Source: Competition Tribunal of South Africa, Competition Commission of South Africa

Yet another reason for the divergence of approaches to merger remedy policy is suggested by Paas (2008), who considers that the size of economies may have an important bearing on the appropriate position of a given country. The author argues that a more favourable approach towards behavioural remedies may be appropriate in small economies, since they are typically more concentrated with higher entry barriers, due to the smaller market size and firms' need to achieve economies of scale. These characteristics make it more likely that mergers with strong efficiency benefits will result in an unacceptable level of concentration and may also make it more difficult to find a suitable buyer for a divested business, both of which suggest that behavioural remedies may have a greater role to play. The author also notes, however, that in the context of increasing trade and globalisation, such effects of smallness are becoming less important. While this argument may have some relevance in the South African context, it is likely only to apply to certain industries where exports are not possible and the domestic market is small. For some manufactured goods, the market is likely to be global in size. 


\section{CASE STUDY: THE MERGER BETWEEN ASTRAL FOODS AND NATIONAL CHICK}

In order to reflect further on the relative merits of the different types of remedy we next present a case study of a South African merger decision involving both structural and behavioural conditions, and consider how effective each was in restoring the pre-merger level of competition.

\subsection{Facts of the case}

In 2010 the Commission conducted an ex-post review of the decision in the merger between Astral Foods and National Chick (Ngwenya \& Robb, 2010), which was approved by the Tribunal in April 2002 (Case number: 69/AM/2001). The conditions attached to the merger approval included both structural and behavioural remedies, and the review produced some interesting insights into the effectiveness of each in practice.

The primary acquiring firm was Astral Foods Limited (Astral), an investment holding company listed on the JSE. At the time of the merger, Astral Group controlled Meadow Feeds (Pty) Ltd, Nutec SA, Ross Poultry, County Fair, Earlybird and Central Analytic Labs. Meadow Feeds was the leading supplier of animal feeds in KwaZulu-Natal, while Ross Poultry was the leading provider of broiler parent stock in South Africa, with a $69 \%$ market share. County Fair and Earlybird were producers of day-old chicks. The target firm was National Chick Limited (Natchix), also an investment holding company listed on the JSE. Natchix was a supplier of day-old chicks. Before the merger, Astral held a $34.9 \%$ share in Natchix, but there was no majority shareholder. Natchix in turn held $55 \%$ of shares in Nutrex Holdings Ltd, which controlled Nutrex (Pty) Ltd, a supplier of animal feed.

Both Astral (through County Fair) and Natchix were involved in a joint venture called Elite Breeding Farms with another independent broiler producer, Country Bird. The partnership supplied parent broilers to Natchix, County Fair and Country Bird with their holdings in the JV being $29 \%, 53 \%$ and $18 \%$ respectively.

The relevant product market in terms of the vertical merger was defined as the market for the supply of day-old chicks and the supply of parent stock. Both parties were involved in the former but were not competitors in respect of supplying chicks to the independent broiler industry, since Astral produced chicks only for its own integrated operations. Natchix was involved in the market for parent stock through its interest in Elite Breeding Farms, which was controlled by Astral and managed by Ross Poultry, Astral's subsidiary. The poultry market is illustrated in FIGURE 2.

The relevant product market for the horizontal aspect of the merger was defined as the market for animal feed. Both parties operated in this market through the subsidiaries Meadow and Nutrex to provide feed to poultry (breeders, broilers and layers), pig and dairy producers.

The Commission found the relevant geographic market to be the Natal-Midlands. 


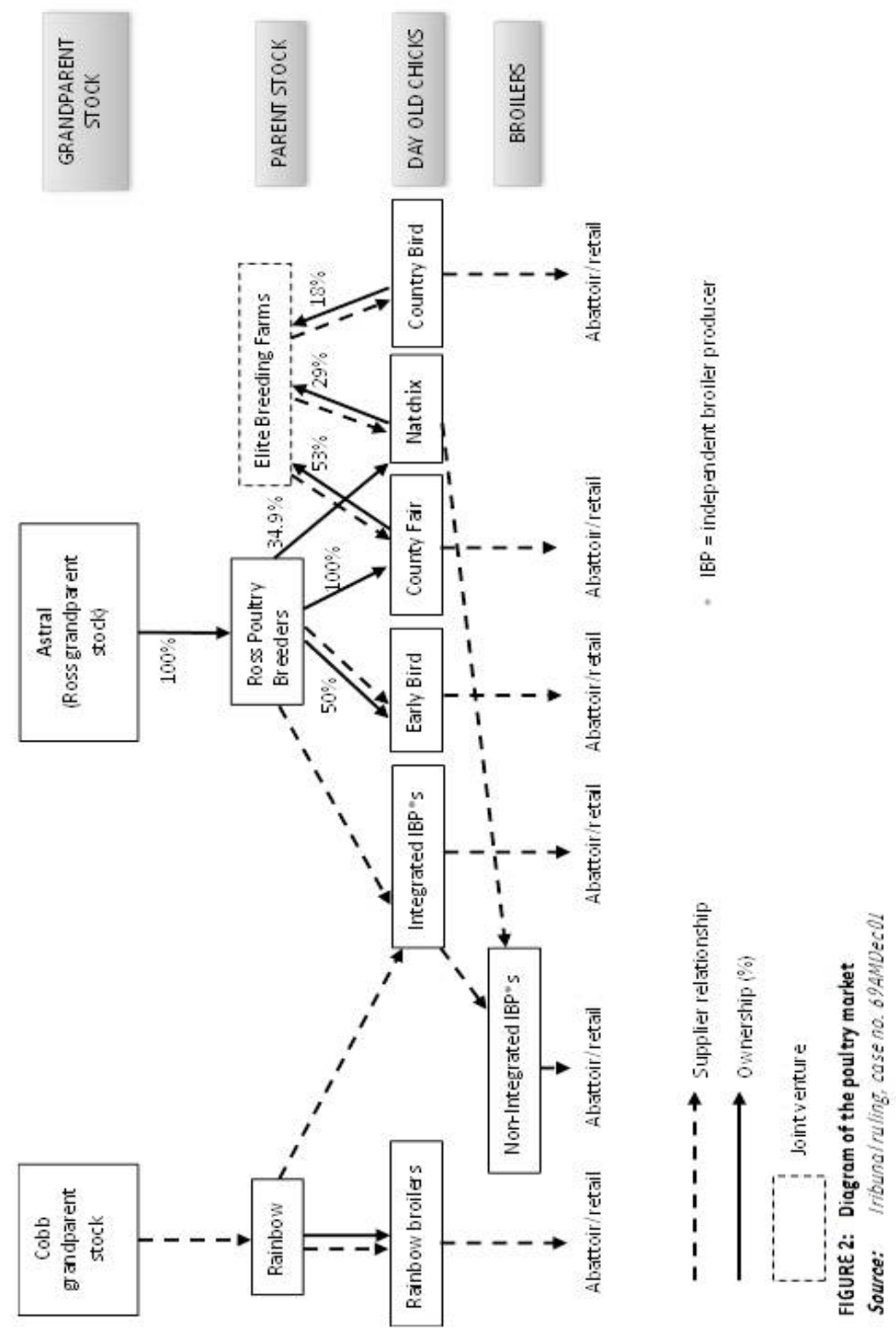




\subsubsection{Vertical concerns}

A number of issues raised concerns about the effects of the merger on competition in the broiler industry. Firstly, Astral was already the leading provider of parent stock in South Africa with a $69 \%$ market share while Natchix was the dominant supplier of day-old chicks in KwaZulu-Natal. Natchix was a supplier to several independent broiler producers, which were direct competitors of Astral's subsidiaries. Therefore the Commission was concerned that Astral could use its dominance in the market for the supply of parent breeding stock to foreclose independent broiler producers downstream by discriminating against competitors with respect to price, service or levels of supply.

To make matters worse, entry barriers in the industry were high, and Cobb, the leading competitor to Ross Poultry as a supplier of parent stock, submitted that it would not have capacity to service significant excess demand for a further five to six years.

The parties, on the other hand, argued that Astral had no incentive to raise prices, as it was merely the franchisee to Ross International, which would be likely to terminate the franchise if it found Astral to be foreclosing buyers of Ross parent stock. In fact, Astral argued that pressure was being put on it by Ross International to increase its market share. The Commission felt, however, that this was not a sufficient countervailing factor to allay its concerns.

\subsubsection{Horizontal concerns}

Furthermore, there were also concerns about the effects of the merger on competition in the market for animal feed. Even before the merger the industry was highly concentrated, and the Commission was of the view that the merger was likely to have an adverse effect on competition in the industry, since Nutrex was shown to be an effective competitor in the Natal-Midlands area. These concerns were felt by the Commission to be serious enough to warrant prohibiting the horizontal aspect of the transaction, and the parties accepted this decision.

\subsubsection{Tribunal decision}

Based on the competition concerns in the two relevant markets, the Commission recommended the prohibition of the merger. However, the Tribunal took a different view. The Tribunal viewed the merger as a circumstance where outright prohibition would be an unnecessarily drastic measure and where behavioural remedies could be effective in addressing the anti-competitive effects without imposing an unreasonable burden on the Commission to monitor.

In terms of the vertica/competition concerns it accepted Astral's argument that in order to keep the Ross International franchise for South Africa, and in view of the stated aims of the main rival Cobb to increase its market share, it would not be able to indulge in any behaviour intended to limit output or make foreclosure likely. It also noted that Astral enjoyed its highest margins upstream (in the market for supply of parent stock), and would therefore have been incentivised to expand supply as widely as possible. Furthermore, the Tribunal was convinced that the merger posed only short-term structural problems that could be remedied by a number of undertakings offered by Astral, including undertakings to enter into a five-year supply contract with each existing customer, to reduce volumes on a pro rata basis in the case of disease etc. and to supply entities in its own group and independent customers on the same terms for equivalent transactions.

On the horizonta/ aspect of the merger the Tribunal concurred with the Commission's analysis and imposed a structural remedy, ordering Astral to divest itself of its entire shareholding in 
Nutrex to an independent purchaser.

\subsection{Market developments post-merger}

Since the merger, the poultry industry has remained highly concentrated, with almost all the major poultry players vertically integrated even up to feed level. The addition of Natchix and, later, Earlybird Farms increased the Astral Group's total broiler production to just below that of Rainbow, its biggest competitor (Ngwenya \& Robb, 2010). In 2006 it was estimated that eight commercial poultry producers handled approximately $74 \%$ of the total poultry supply in South Africa (Ngwenya \& Robb, 2010). Of the 27 poultry feed companies in South Africa, three (Meadow, Epol and Afgri) supply $75 \%$ of the total poultry feed manufactured in the industry (SAPA, 2006). While this may be beneficial in terms of eliminating the possibility of double marginalisation, it could also raise entry barriers and inhibit smaller firms from being effective competitors through the foreclosure of inputs. For example, the necessary genetic stock may not be made available to competitors on equivalent terms, as suppliers favour their own operations.

A number of specific competition concerns have been noted in the poultry industry since the merger. The merger approval effectively gave Astral the majority shareholding in Elite, the joint venture between Astral and Country Bird described above, a consequence that was not considered by the Tribunal and that has resulted in a complaint by Country Bird against Astral and Elite, which the Commission investigated under Sections 4 and 8 of the Competition Act (case number: 2009Apr4389). The case is currently awaiting adjudication by the Tribunal (case number: 74/CR/Jun08), but may provide support for the Commission's original concern that the merger could lead to the foreclosure of a sizeable portion of the parent stock market.

FIGURE 3a illustrates the increase in Astral's margins, which was achieved from the time of the merger until Country Bird's exit from the JV and entry into the market for parent stock. These margins then declined steeply after 2006, coinciding with Country Bird's successful entry. At first glance, it seems that the merger may have allowed Astral to further entrench its dominant position in the poultry industry until entry occurred.

In order to investigate possible alternative reasons for the trends in margins, FIGURES $\mathbf{3 c}$ and $\mathbf{3 d}$ plot the farm feed price index and per capita consumption of white meat against Astral's margins in order to establish whether increasing input costs or declining demand could be the reason for the sharp fall in margins after 2006 . Feed prices increased throughout the period, but accelerated after 2006 . Consumption of white meat was relatively stable around 2000 , began to increase in 2002 and then increased very steeply after 2004. After 2006 consumption continued to increase, but at a much slower rate.

FIGURE $3 \mathbf{b}$ shows the margins of Rainbow, the main competitor to Astral and of Country Bird after its entry in 2006. These suggest that Rainbow may also have benefited from the increased concentration in the industry with increasing margins until 2006. Rainbow's margins fell more slowly than Astral's after 2006; however, this may be accounted for by the fact that it was not possible to get data on Rainbow's margins from poultry only, and these also include earnings from its feed business where prices were rising.

Country Bird appears to have entered very successfully, earning an operating profit of around $17 \%$ in 2006 . After this point, the profits of all the companies fell sharply. While this would have been influenced by the steeper increase in feed prices and the flattening off of demand for poultry, it may also indicate an increase in competition in the industry. 
Robb \& Ngwenya
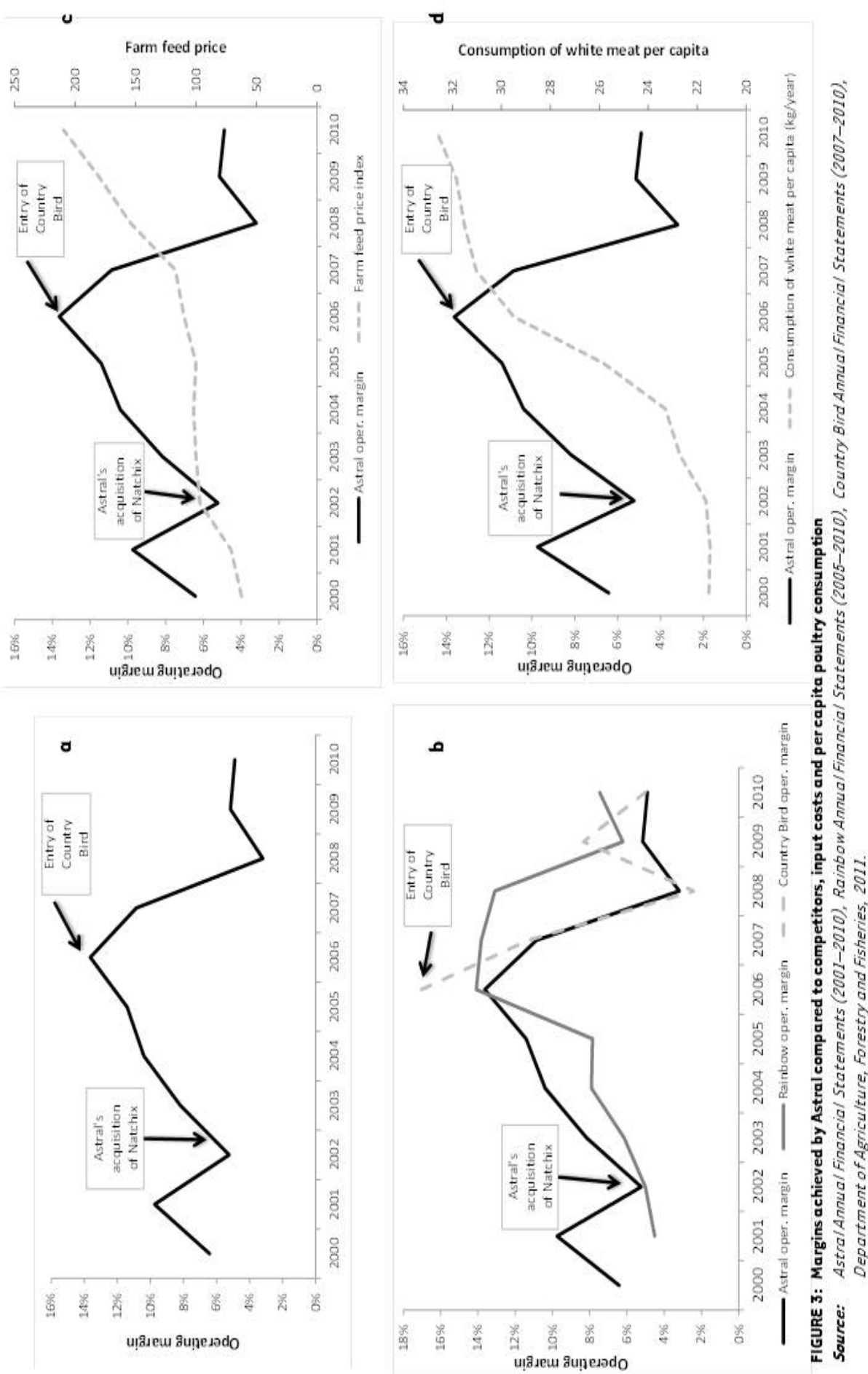
One would expect some part of the cost increase in terms of feed prices to be passed on to consumers, and at the time demand was not actually falling, it merely increased more slowly. Therefore, it is surprising that there was such a sharp drop in margins, unless part of the decrease is also explained by increasing levels of competition among poultry producers. The most likely scenario seems to be that the entry of Country Bird resulted in an increase in supply in the industry, which, combined with rising input costs and constant demand, would lead to falling margins.

Although successful entry did eventually occur in 2006, which was followed by falling margins, this does not seem likely to have been facilitated by the behavioural conditions, since Country Bird was only able to enter as Astral's five-year behavioural commitment was coming to an end.

Furthermore, in April 2009 the Commission initiated an investigation into possible anticompetitive behaviour in the South African poultry industry (Commission case numbers: $2009 \mathrm{Apr} 4389,2009 \mathrm{Apr} 4390$ and 2009Apr4391). The structure and concentrated nature of the poultry industry led to concerns about possible anti-competitive conduct by the vertically integrated firms. This is particularly worrying, since it could lead to higher prices for what is a staple food product. The investigation is still on-going; however, the Tribunal's conditional approval of the Astral/Natchix merger may have accentuated some of the concerns observed in the industry.

\subsection{Effectiveness of the remedies}

\subsubsection{Structural remedy to address the horizontal concerns}

The Tribunal included some of the precautions discussed in the literature review to try to maximise the effectiveness of the structural remedy. Hold-separate conditions were imposed: Astral was to have no role in the management of Nutrex, and no access to the company's books of records during the interim period. No monitoring trustee was to be appointed; however, if Astral failed to divest Nutrex to a Commission-approved buyer within the specified time limit, then it would be forced to appoint a trustee who would have a mandate to sell at whatever price he determined. Thus there was an incentive for Astral to conclude the sale quickly, and to a purchaser that the Commission would endorse as a separate entity with the ability to be a viable competitor. An additional precaution could have been to require the appointment of a monitoring trustee for the entire interim period, with a brief to monitor the behaviour of Astral and Nutrex and report to the Commission on whether the hold-separate conditions were being adhered to and the value of Nutrex's assets maintained. However, the lack of this provision does not seem to have had a negative impact on the outcome in this case, perhaps because the asset to be divested was an entirely separate entity that was relatively easy to keep apart from the merged firm.

In the course of the merger review the Commission interviewed a number of industry players to gain insight into the effectiveness of the conditions imposed. Those interviewed were of the view that Nutrex had become an effective competitor and alternative to Meadow Feeds (Astral) and Epol (Rainbow) in KZN, although due to capacity constraints buyers are still obliged to buy a certain percentage of their feed from the larger companies. In general those interviewed expressed their satisfaction with the effectiveness of the structural remedy (Ngwenya \& Robb, 2010). The remedy seems to have had the effect of restoring the pre-merger level of competition in the animal feed market.

Overall, the review of the structural remedy provides support for the theory that divestiture is 
more likely to be effective when an entire on-going business is divested. The structural remedy imposed in the Astral/Natchix merger does not seem to have suffered from any of the problems sometimes experienced by structural remedies, probably because of the extra provisions put in place by the Tribunal, as described above. The review suggests that a well-designed and carefully implemented structural remedy can be very effective in restoring the pre-merger level of competition in a one-off transaction without costly on-going monitoring by the CA.

\subsubsection{Behavioural remedy to address the vertical concerns}

The discussion above around the post-merger development of the market highlights that the behavioural remedies imposed have not been completely successful in preventing the foreclosure of independent broiler producers. The merger review completed by the Commission suggests a reason for this, since it states that compliance monitoring of the remedy was almost impossible due to capacity and resource constraints (Ngwenya \& Robb, 2010). It seems, therefore, that some of the concerns with behavioural remedies that are mentioned in the literature have been borne out in the merger under review. In particular, behavioural remedies are shown to require on-going monitoring, and, in the absence of this, are likely to be easily evaded. Furthermore, it provides support for the $\varepsilon U$ finding that access remedies are difficult to enforce and often ineffective.

This review looks at one merger only, and so we cannot conclude from this very limited sample that structural remedies are always superior to behavioural ones. However, it does indicate that careful consideration of the appropriateness of different remedies should include a realistic review of the ability and capacity of the CA to play an on-going role in the monitoring of compliance when deciding which remedies to impose.

Furthermore, should the Commission's on-going investigation reveal that these foreclosure and tying practices were still occurring in the poultry industry, it would represent further evidence that the behavioural conditions imposed by the Tribunal did not have the desired outcome of promoting competition to the benefit of consumers and preventing foreclosure of smaller independent competitors in the industry.

\section{CONCLUSION AND AREAS FOR FUTURE RESEARCH}

The international comparison highlighted that there is no broad consensus on what the optimal remedy policy should be. On the contrary, jurisdictions can be grouped into two distinct categories depending on whether they rely more heavily on structural or on behavioural remedies to ameliorate the competition concerns generated by mergers. From the data it is clear that South Africa sits firmly in the latter grouping, along with various Southern and Eastern European countries, and in contrast to the expressed preferences and conduct of the $\varepsilon C, U S$, UK, Germany and the Netherlands. The reason for this divergence in practice is not entirely clear. It may be, as advanced by Hoehn (2009), that it is the greater experience of the more established competition authorities that has led them to be "tougher" in their choice of remedy. It is also possible that differences in the size and structure of economies and specific industries across countries influence the CAs' inclination towards one or other type.

Whichever is the more accurate hypothesis (and it could be that there is some truth in both), the divergence serves to highlight the lack of certainty around what the optimal mix of structural and behavioural remedies would be. In this context it is certainly appropriate to interrogate further the South African authorities' strong preference for behavioural remedies. Both the 
literature review and the case study presented highlight the difficulties associated with behavioural remedies, and bring into question their effectiveness in the absence of strict monitoring and enforcement. Behavioural remedies are much easier for firms to evade than structural remedies. In the context of a resource-constrained authority it is questionable whether a preference for behavioural remedies is appropriate, except in industries where an effective sector regulator already exists. In particular in mergers where there are horizontal competition concerns, behavioural remedies often amount to an undertaking not to behave in an anticompetitive manner, a commitment which is given little credence by the $\varepsilon C$ and the US authorities. It is consequently surprising to see that, although less marked than in vertical mergers, South Africa still shows a preference for behavioural remedies in horizontal mergers.

In order to answer the question of what kind of remedy policy is most appropriate for South Africa it would be useful to conduct further research into the effectiveness of behavioural remedies in past merger cases. In particular, research should focus on whether monitoring and enforcement of the remedies has been present and effective, and whether the affected markets retained their pre-merger level of competition. Future research could also seek to explain the differences in remedy policy across jurisdictions in order to confirm or reject the hypotheses advanced above. In particular, it would be useful to explore in greater detail the ways in which South African markets may be different from other countries and the extent to which this should inform preferences for certain remedies. Finally, to extend the analysis to include mergers prohibited or abandoned would provide a more complete picture of merger policy in each jurisdiction.

\section{LIST OF REFERENCES}

Astral Foods. (2001 - 2010). Annual Reports 2001-2010. [0n-line] Available: http://www.astralfoods.co.za. (Accessed 5 September 2011).

Baer, W. J. (1999). A Study of the Commission's Divestiture Process. US Federal Trade Commission. [On-line] Available: http://www.ftc.gov/os/1999/08/divestiture.pdf. (Accessed 5 September 2011).

Barros, P., Clougherty, J. \& Seldeslachts, J. (2007). Remedy for Now but Prohibit for Tomorrow: The Deterrence Effects of Merger Policy Tools. Social Science Research Centre, Berlin, SP II 2007 - 02.

Clifford Chance and PricewaterhouseCoopers. (2008). The merger remedies matrix synthesis report: $A$ European cross-country comparison of merger remedies: Experience and practice, 18 December 2008. [On-line] Available:

http://www.competitionrx.com/documents/ArticlesAndReports/CompetitionRx_5.pdf. (Accessed 5 September 2011).

Country Bird Holdings Limited. (2007 - 2010). Annual Reports 2007-2010. [0n-line] Available: http://www.cbh.co.za. (Accessed 5 September 2011).

Department of Agriculture, Forestry and Fisheries. (2011). Abstract of agricultural Statistics 2011. [On-line] Available: http://www.nda.agric.za/docs/statsinfo/Abstract_2011.pdf. (Accessed 5 September 2011).

European Commission. (2005). Merger Remedies Study. DG Competition, European Commission, October 2005. [0n-line] Available:

http://ec.europa.eu/competition/mergers/legislation/remedies_study.pdf. (Accessed 5 September 2011). 
European Commission. (2008). Commission notice on remedies acceptable under Council Regulation (EC) No 139/2004 and under Commission Regulation (EC) No 802/2004, 2008/C 267/01. [On-line] Available:

http://ec.europa.eu/competition/mergers/legislation/files_remedies/remedies_notice_en.pdf. (Accessed 5 September 2011).

Hoehn, T. (2009). Structure versus conduct - a comparison of the national merger remedies practice in seven European countries. Paper presented at the Conference on the Ex-post Evaluation of Competition Policy organised by the Centre for European Economic Research (ZEW) Mannheim, 3-4 June 2009. [On-line] Available:

http://www.competitionrx.com/documents/ArticlesAndReports/CompetitionRx_10.pdf. (Accessed 5 September 2011).

International Competition Network. (2005). Merger Remedies Review Project. Report for the fourth ICN Annual Conference, ICN Merger Working Group: Analytical Framework Subgroup. Bonn - June 2005. [On-line] Available: http://www.internationalcompetitionnetwork.org/uploads/library/doc323.pdf. (Accessed 5 September 2011).

Motta, M. (2005). Competition Policy: Theory and Practice. New York: Cambridge University Press.

Motta, M., Polo, M. \& Vasconcelos, H. (2002). Merger Remedies in the European Union: An Overview. Paper presented at the Symposium on Guidelines for Merger Remedies - Prospects and Principles, Ecole des Mines, Paris, January 17-18, 2002.

Ngwenya, A. \& Robb, R. (2010). Theory and practice in the use of merger remedies: considering South African experience, September 2010. [On-line] Available: http://www.compcom.co.za/fourthcompetition-law-conference/. (Accessed 5 September 2011).

Paas, K. (2008). Implications of the Smallness of an Economy for Merger Remedies. Juridica International, 15, pp. 94-103.

Papandropoulos, P. \& Tajana, A. (2005). The Merger Remedies Study - In Divestiture We Trust? European Competition Law Review, 8, pp. 443-454.

Rainbow Chicken Limited. (2005 - 2010). Annual Reports 2005-2010. [0n-line] Available: http://www.rainbowchicken.co.za. (Accessed 5 September 2011).

United Kingdom Competition Commission. (2010). Understanding past merger remedies: report on case study research, September 2010. [0n-line] Available: http://www.competitioncommission.org.uk/our_role/analysis/understanding_past_merger_remedies.pdf. (Accessed 5 September 2011).

United States Department of Justice. (2004). Antitrust division policy guide to merger remedies, October 2004. [On-line] Available: http://www.justice.gov/atr/public/guidelines/205108.htm. (Accessed 5 September 2011). 